\title{
Coulisse mechanism with rotating link for operating part drive unit of the mortar pump
}

\author{
Bakhtiyar Alimov", Rakhmat Sindarov, Panzhi Egamshukurov, Fotima Dzhumabayeva, \\ and Shoira Saidova \\ Tashkent State Transport University, Tashkent, Uzbekistan
}

\begin{abstract}
The synthesis of a connecting link mechanism with a rotating link with a planetary gear for driving the operating part of a piston pump during transportation of solution mixtures from the preparation site to the construction site is presented. The kinematic diagram of the axial and disaxial connecting link mechanism is given, which allow increasing the pump performance by increasing the length of the piston stroke $\mathrm{S}$ by $1.7 \ldots$ 3 times more than the serial pumps produced and reducing the load on the pump bearing support.
\end{abstract}

\section{Introduction}

The production of mortar mixtures at factories with high productivity allows reaching a production up to $Q=15 \mathrm{~m}^{3}$ per worker per shift, which reduces the cost of preparing mortar mixtures by $5 \div 8$ times compared to preparing them at small installations. Abroad (Skopinsk, Russia), crank-connecting rod piston pumps of the SSCH-50F, S-284 F, etc. brands are produced, which allow moving solutions along the pipeline at a distance of up to $\mathrm{L}=250 \div 350 \mathrm{~m}$ horizontally, and height $\mathrm{H}=40 \mathrm{~m}[1,2]$. Piston pumps are widely used [3-7]. Reciprocating piston pumps are produced by the firms "Vibau", "Putzmeister", "Schwing" (Germany), "Worthington" (Italy), "Niigata" (Japan), etc. [8, 9].

\section{Methods}

The article proposes theoretical developments of the coulisse mechanism for driving the operating part of a piston pump, which were carried out according to the methodology of the main provisions of the theories of mechanisms and machines, construction machines and pumps.

\section{Results and discussion}

We have proposed a kinematic diagram (Figure 1, a, b) of a rocker mechanism with a planetary gear to drive the operating part of a piston pump when transporting solution mixtures. The solution mixture (Figure 1, a) from the receiving hopper 1 is fed by paddle

\footnotetext{
*Corresponding author: alimov-1946@mail.ru
} 
devices 2 and 3, in which it is continuously moving, to the suction valve 4 of the pump cylinder. After filling the cylinder, the suction valve 4 closes, and the subsequent discharge valve 5 opens. The mortar mixture is squeezed out in the pump cylinder under the pressure of the piston 6 , which is driven by a crank mechanism $(7,8,9)$. With the reverse movement of the piston 6 , the discharge valve 5 closes, the suction valve 4 opens, and the cycle repeats.

The crank-connecting rod mechanism (Figure 1, b) is driven by an electric motor 10 by means of a gearbox, which consists of a planetary reducer $11[12,13]$ and a simple gear train $Z_{4}$ and $z_{5}$. The transmission of the mechanism is driven by a crank 9 , a slider 12 and a rocker 13. Between the slider 12 and the crank 9, a connecting rod 8 is installed, connected through a rod 7 and a piston 6 .

The main part of the mortar pump is piston 6 , which moves in the pump cylinder. The outer surface of the piston 6 fits snugly against the well-machined surface of the pump cylinder. The piston 6 moves reciprocally and moves under the influence of the crank mechanism $(7,8,9)$ acting on the rod 7 . When the slider 12 moves to the right, the piston 6 makes a working stroke, and when the slider 12 moves to the left, an idle stroke occurs.
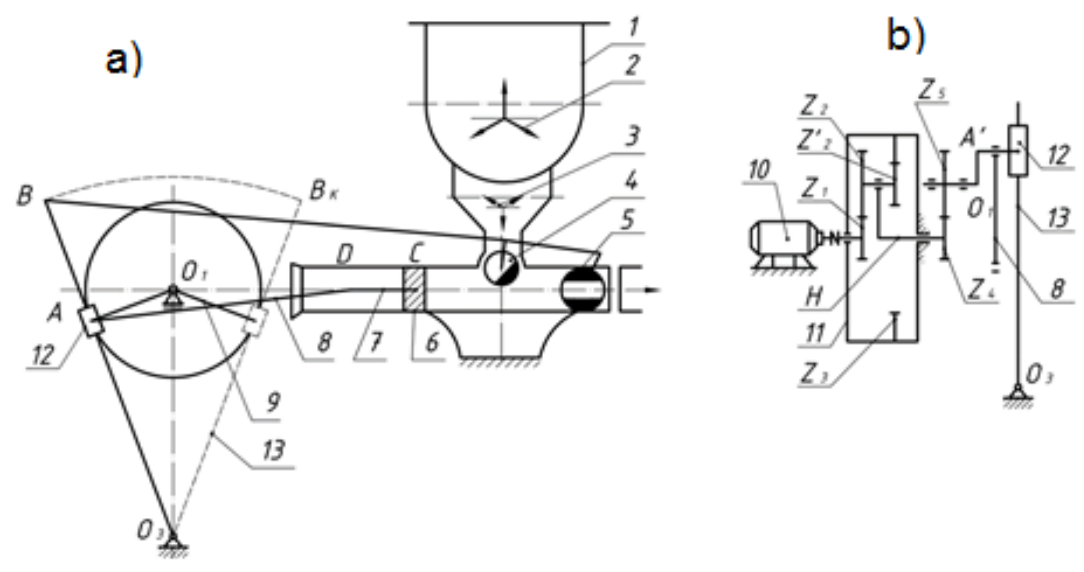

Fig. 1. Kinematic diagram of the coulisse mechanism (a) and drive (b) of the operating part of the piston pump

To convert the rotational movement of the crank $O_{1} A$ into the reciprocating movement of the slider 12 is used the coulisse mechanism $O_{1} A O_{3} B$. The crank 9 rotates at a constant angular velocity $\omega_{1}$ and the coulisse $O_{3} B$ swings about a point $O_{3}$. The coulisse mechanism allows obtaining a high reverse speed, i.e. idle move. To obtain the required main piston speed is used a planetary gear reducer $[14 \ldots 20]$.

Multi-link coulisse mechanisms are used as six-link mechanisms. The executive link of these mechanisms, the slider 6 , makes a reverse movement, i.e. makes a forward-reverse movement in the hydraulic cylinder.

By design, coulisse mechanisms are divided into two types:

1 - mechanisms with a swinging coulisse, at $r<a$, (Figure 1, a);

2 - mechanisms with a rotating coulisse, at $r>a$, (Figure 2, a, b);

here is $r=O_{1} A$ the crank radius; $a=O_{1} O_{2}$ - between an axial distance of the center of two supports of the crank $O_{1}$ and the link $O_{2}$. 
If in the coulisse mechanism (Figure 2, a, b) the radius $r$ of the crank is greater than between axial distance $a$ of the coulisse mechanism $r>a$, then the rocker mechanism $\mathrm{O}_{2} \mathrm{AB}$ can rotate a whole turnover, and the coulisse mechanism is with a rotating link. Otherwise, when $r<a$ a mechanism with a swinging coulisse is obtained (Figure 1, a).

Consider two structural schemes of the coulisse mechanism - with a swinging (Figure 1, a) and rotating (Figure 2, a, b) coulisse, when the center distance $a$ is greater than the radius $\mathrm{r}$ of the crank $-a>r$ and less $-a<r$.

When designing machines at installing a mechanism, the first stage in the development of this design is the choice of the optimal kinematic scheme of the mechanism, the second stage is the configuration detail units of the given installation of construction, and the third stage is the development of working drawings for this installation.

For a better comparison when choosing the optimal design of the mechanism from having two kinematic schemes of the coulisse mechanism - with a swinging and rotating coulisse, we set the same parameters for them, i.e. when designing the optimal design of the mechanism, they are set by part of the main links, i.e. when designing the kinematic scheme of the coulisse mechanism (Figure 1, a), the dimensions of the links of the mechanism are determined according to the given conditions: the length of the radius $r$ of the crank, the length of the radius $R$ of the link $O_{2} B$, the length of the connecting rod $l_{A C}$, the ratio coefficient $\lambda$ of the length of the connecting rod $l_{A C}$ to the length $O_{2} B$ of the radius $R$ of the stage and are assumed to be the same for both mechanisms.

The criterion for evaluating the choice of the optimal kinematic scheme of the coulisse mechanism for the operating part of the piston pump is:

1. The resulting overall dimensions of the coulisse mechanism, which affects the metalconsuming structure of the machine and its high cost;

2. Obtaining the value of the operating criterion $(\sigma=1 \div 3)$ or the rate of increase in the speed of the reverse (idle) stroke $\mathrm{S}$ of the piston in the hydraulic cylinder of the pump.

If in the coulisse mechanism the radius $r$ of the crank is greater than the center distance, and the center of the two bearings of the crank is $O_{1}$ and the coulisse $O_{2}$, i.e. $\mathrm{r}>$ a, then the coulisse $\mathrm{O}_{2} \mathrm{AB}$ rotates a whole turnover (Figure 2, a and b) and the coulisse mechanism is with a rotating coulisse.

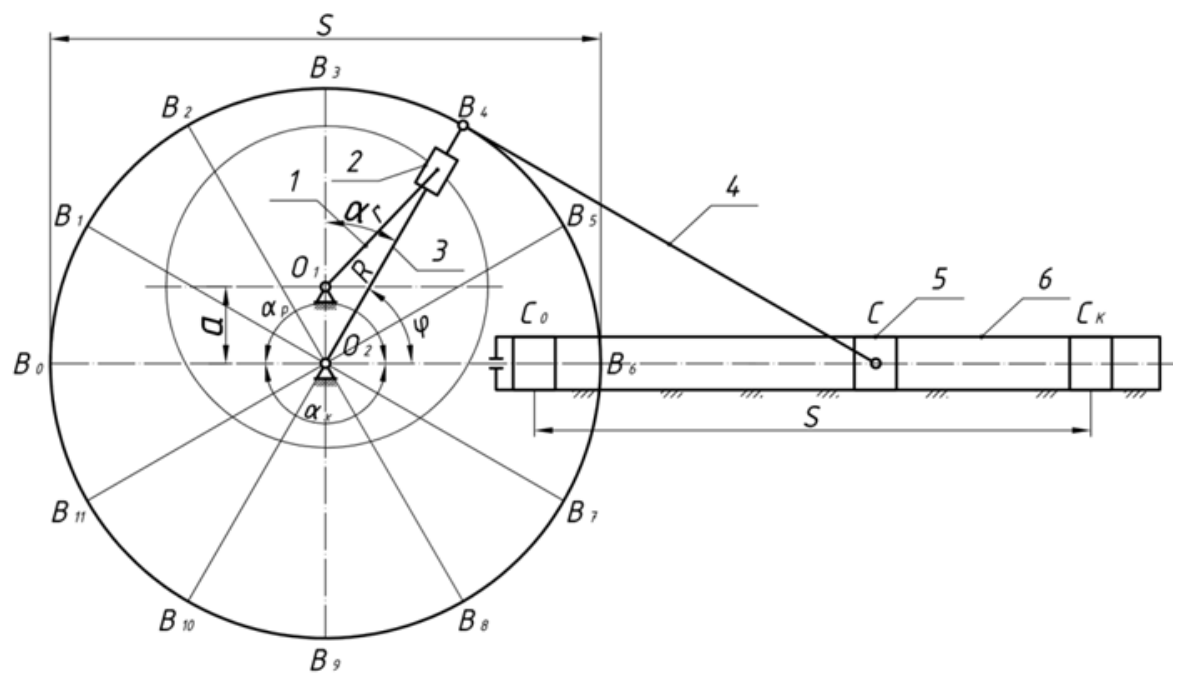

a) 


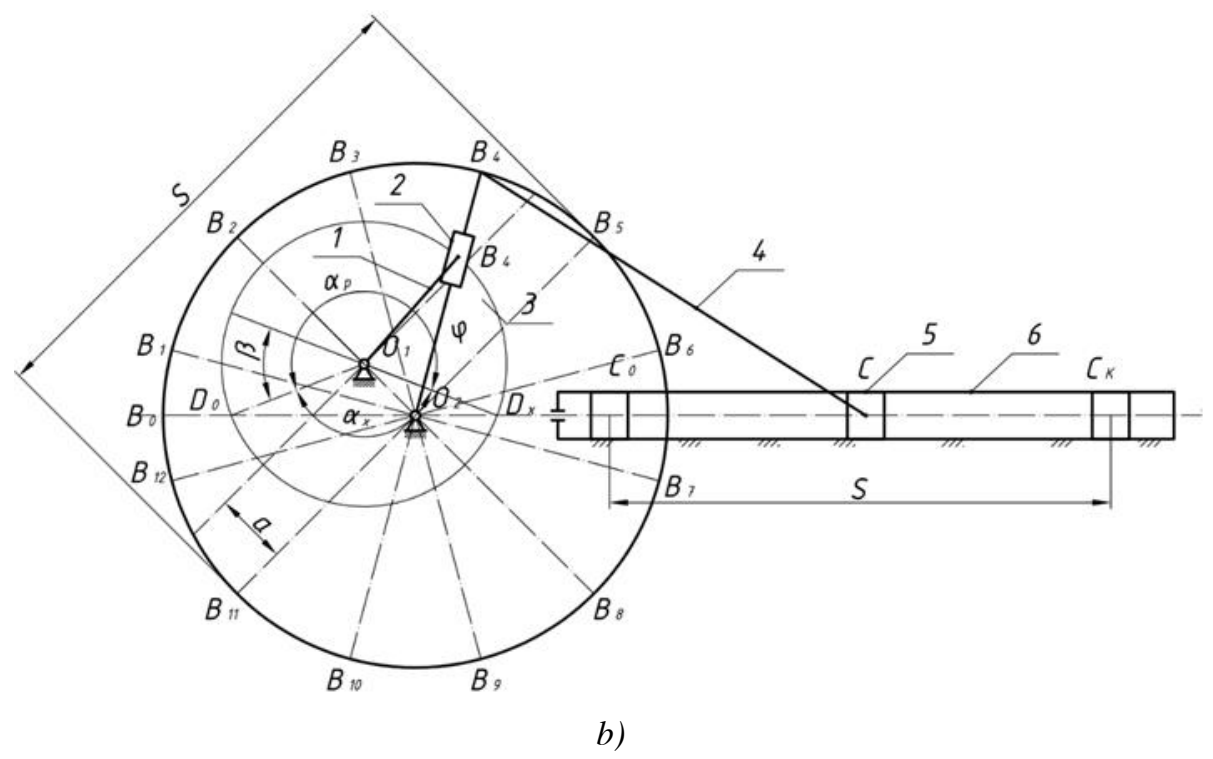

Fig. 2 - Kinematic scheme of a coulisse mechanism with a rotating link: - axial mechanism; b) deaxial mechanism.

a) the six-link mechanism with a rotating swing coulisse for driving the operating part of the piston pump (Figure 2, a and b) consists of the following links: 1 is crank; 2 is slider; 3 is link; 4 is connecting rod; 5 is piston and 6 is pump hydraulic cylinder.

By the type of location of the slider structure of the centerline of the movement of the guide horizontally or when displaced from it, the mechanisms are divided into:

1. - axial coulisse mechanism (Figure 2, a)

2. - disaxial coulisse mechanism (Figure 2, b)

Choosing the numerical values of the radius $r$ of the crank, $r=0,3 \mathrm{M}$; curtain radius $R=1,0 \mathrm{M}$ and ratio coefficient $\lambda=3.5$ then we will have:

a) for the swinging stage

Find the stroke length $\mathrm{S}$ of the pump piston (Figure 1, a)

$$
S=2 R \sin \frac{\varphi_{\mathrm{K}}}{2}
$$

Where $\varphi_{\mathrm{K}}$ is the swing of the oscillatory angle of the coulisse $O_{2} B_{1}(R)$

$$
\varphi_{k}=\pi \frac{K-1}{K+1}
$$

Where $\mathrm{K}$ is the coefficient of change in the average speed of the pump piston, with $K=2$, then we get

$$
\varphi_{\mathrm{K}}=\pi \frac{K-1}{K+1}=180^{\circ} \frac{2-1}{2+1}=60^{\circ}
$$

substituting the obtained value $\varphi_{\mathrm{K}}=60^{\circ}$ into equation (1), we obtain

$$
S=2 R \sin \frac{\varphi_{k}}{2}=2 \cdot 1.0 \cdot \sin 30^{\circ}=1.0 \mathrm{~m}
$$


According to the obtained values $S=1.0 \mathrm{~m}$, we got an isosceles triangle $O_{2} B_{1} B_{\mathrm{K}}$, i.e. the height $H$ and length $L$ of the coulisse mechanism received the same value $S=1,0 \mathrm{~m}$. Determine the length of the connecting rod $l_{B C}$ of the piston pump

$$
l_{B C}=\lambda r=3.5 \cdot 0.3=1.05 \mathrm{~m}
$$

Determine the length of the $\operatorname{rod} l_{C D}$ of the piston pump

$$
l_{C D}=1.1 \cdot S=1.1 \cdot 1.0=1.1 \mathrm{~m}
$$

Determine between axial distance $a$ of the center of two supports of the crank $O_{1}$ and the link $\mathrm{O}_{2}$

$$
a=\frac{r}{\sin \varphi_{\mathrm{K}} / 2}=\frac{0,3}{\sin 30^{\circ}}=\frac{0.3}{0.5}=0,6 \mathrm{~m}
$$

The exploitation criterion $\sigma$ is the ratio of the travel time $t_{\mathrm{p}}$ to the idle time $t_{\mathrm{x}}$ or the rate of increase in the reverse speed:

$$
\sigma=t_{\mathrm{p}} / t_{\mathrm{x}}=\frac{\left(\pi+\varphi_{\mathrm{K}}\right)}{\left(\pi-\varphi_{\mathrm{K}}\right)}
$$

Substituting the numerical values, we get

$$
\sigma=\frac{t_{\mathrm{p}}}{t_{\mathrm{x}}}=\frac{\left(\pi+\varphi_{\mathrm{K}}\right)}{\left(\pi-\varphi_{\mathrm{K}}\right)}=\frac{\left(180^{\circ}+60^{\circ}\right)}{\left(180^{\circ}-60^{\circ}\right)}=\frac{240^{\circ}}{120^{\circ}}=2
$$

b) for a rotating axial stage

Axial coulisse mechanisms with a rotating coulisse (Figure 2, a) are used for uniform movement of the piston 5 since the phase angles $\varphi_{\mathrm{p}}$ and $\varphi_{\mathrm{x}}$ are equal to $180^{\circ}$, i.e. with uniform rotation of the crank 1, the forward and reverse stroke $S$ of the slider 5 of the piston pump are performed in the same time

$$
t_{\mathrm{p}}=t_{\mathrm{x}}=\text { Const }
$$

Find the stroke length $S$ of the pump piston

$$
S=2 R=2 \cdot 1,0=2 m
$$

Determine the length of the connecting rod $l_{B C}$ of the piston pump

$$
l_{B C}=\lambda r=3.5 \cdot 0.3=1.05 \mathrm{~m}
$$

Determine the length of the $\operatorname{rod} l_{C D}$ of the piston pump

$$
l_{C D}=1.1 \cdot S=1.1 \cdot 1.0=1.1 \mathrm{~m}
$$

Determine between axial distance $a$ of the center of two supports of the crank $O_{1}$ and the link $\mathrm{O}_{2}$

$$
a=\frac{l_{O_{2} A}}{\cos \varphi_{\mathrm{K}}+\lambda \cos \psi}=\frac{1,0}{1+3,5 \cdot 1}=0.22 \mathrm{~m}
$$

Using equation (5), we find the operational criterion $\sigma$ :

$$
\sigma=\frac{t_{\mathrm{p}}}{t_{\mathrm{x}}}=\frac{\left(\pi+\varphi_{\mathrm{K}}\right)}{\left(\pi-\varphi_{\mathrm{K}}\right)}=\frac{180^{\circ}}{180^{\circ}}=1
$$


c) for a rotating deaxial stage

Disaxial coulisse mechanisms with a rotating coulisse (Figure 2, b) are used for uneven movement of the piston 5, since the phase angles $\varphi_{\mathrm{p}}$ and $\varphi_{\mathrm{x}}$ are unequal, i.e. with uniform rotation of the crank 1, the forward and reverse travel $\mathrm{S}$ of the slider 5 of the piston pump are performed for unequal time, $t_{\mathrm{p}}>t_{\mathrm{x}}$.

The angle $\varphi_{\mathrm{K}}$ between the horizontal plane $O_{2} B_{4}$ and $O_{2} C$ (Figure 2, b) is set by different $\varphi_{\mathrm{K}}=30^{\circ} \ldots 90^{\circ}$, while the coefficient of increase in the average speed $\mathrm{K}$ will be greatest at $\varphi_{\mathrm{K}}=90^{\circ}$, so choose $\varphi_{\mathrm{K}}=90^{\circ}$.

Using equation (5), we find the operational criterion $\sigma$ :

$$
\sigma=\frac{t_{\mathrm{p}}}{t_{\mathrm{x}}}=\frac{\left(\pi+\varphi_{\mathrm{K}}\right)}{\left(\pi-\varphi_{\mathrm{K}}\right)}=\frac{\left(180^{\circ}+90^{\circ}\right)}{\left(180^{\circ}-90^{\circ}\right)}=\frac{270^{\circ}}{90^{\circ}}=3
$$

\section{Conclusions}

The advantages of the proposed kinematic scheme are:

1. The use of a deaxial coulisse mechanism to drive the working member of a piston pump contributes to an increase in the operating criterion $\sigma$ and a significant stroke of the length $\mathrm{S}$ of the piston 3 times greater than that serial pumps produced, which leads to an increase in pump performance.

2. Low loads on the supports, which makes it possible to simplify the design of the supports and reduce losses in them.

\section{References}

1. Ushakov B.I., Danilov E.I., Egorov V.M. Prospects for the development of equipment for concrete and mortar works. Proceedings of TSNIITE Stroymash. Issue (112) M, p 129, (1999).

2. Slesarev Yu.M. Preparation of concrete mix and mortar. Proceedings of TSNIITE Stroymash. Issue (109) M, p 133, (1998)

3. Popov V.V. The pump for viscous and inhomogeneous liquids, Inventor's certificate No. 1399500 BI No. 20 dated 05/30/88.

4. Strekalov V.E. Pump for pumping viscous and inhomogeneous liquids, Copyright certificate No. 909281 BI No. 8 dated 02.28.82.

5. Nizamiev F.Kh. Pump for pumping viscous liquids, Inventor's certificate No. 1525304 BI No. 44 dated 30.11.89.

6. Boyko NV, et al. Concrete pump, Copyright certificate No. 558108 BI. No. 18 dated 05.15.77.

7. Glebov V.V. Piston pump, Inventor's certificate No. 510586 BI No. 14 dated 04.15.76.

8. Alimov B.M., Urazkeldiev A.B., Edylbaev U. Kinematic study of the rocker mechanism for driving the working body of a piston pump for viscous and inhomogeneous liquids, Magazine "Young Scientist" 9 (68), June 2014 Russia. (2014).

9. Alimov B.M., Urazkeldiev A.B., Edylbaev U. The use of a rocker mechanism to drive the working body of a piston pump, Magazine "Young Scientist" 9 (68), June 2014 Russia, (2014).

10. Prabhakar V Pawar, Kulkarni P.R. International Journal of Mechanical Engineering and Information Technology, 3. (3). March 2015. pp.1067-1073, (2015). 
11. Tristan M. Ericson, Robert G. Parker, "Experimental measurement of the torque on dynamic behavior and system parameters of planetary gears" MMT 74 (2014), pp. 370-389.

12. Shyi-Jeng Tsai, Guan-Lin Huang, Siang-Yu Ye "Gear meshing analysis of planetary gear sets with a floating sun gear" Mechanism and Machine Theory (2014) VAMT02278 .

13. Dr. Alexander Kapelevich "High Gera Ratio Epicyclic Drives Analysis" GEAR TECHNOLOGY / June 2014 pp: 61-67. (2014)

14. D.R. Salgado, J.M. del Castillo "Analysis of the transmission ratio and efficiency ranges of the four-, five-, and six-link planetary gear trains" MMT-73, pp. 218-243. (2014)

15. Bernd-Robert Hohn, Karsten Stahl and Philipp Gwinner "Light-Weight Design for Planetary Gear Transmissions" GEAR TECHNOLOGY, Sept. 2013 pp. 96-103. (2013)

16. Cheon-Jae Bakh, Robert G. Parker "Analytical investigation of tooth profile modification effects on planetary gear dynamics" Mechanism and Machine Theory (70). pp: 298-319. (2013).

17. Syed Ibrahim Dilawer, Md. Abdul Raheem Junaidi, Dr. S. Nawazish Mehdi "Design, Load Analysis and Optimization of Compound Epicyclic Gear Trains" American Journal of Engineering Research ISSN 2320-0936 (02), Issue-10, pp: 146-153.(2013).

18. Nehad Marjanovic, Biserka Isailovic, Vesna Marjanovic, Zoran Milojevic, Mirko Blagojevic, Milorad Bojic, "A practical approach to the optimization of gear trains with spur gears" Mechanism and Machine Theory 53 pp: 1-16. (2012)

19. Jelena Stefanovic-Marinovic and Milos Milovancevic "Load Allocation and Equilibrium for Planetary Gear Reducers of Earth-Pressure-Balance Shield Machine" Journal of Engineering and Automation 2 pp: 365-373. (2012).

20. Juraj Jablonick Lubom Huj, Zdenko Tkc, J. Kosiba, "3D Model of the Differential Planetary Gear and the Kinematic and Force Analysis" HTHPY-2012, том 51 pp. 171-181. (2012).

21. Wen-Hsiang Hsiehl, Shoa-Jui Chen "Innovative Design of Cam-Controlled Planetary Gear Trains" International Journal of Engineering and Technology Innovation, 1, (1), pp. 1-11.(2011) 